\title{
A HYBRID APPROACH TO CHARGE MOBILE PHONE BATTERY BY SOUND
}

\author{
ENERGY \\ Vikram-Srivastava, DEPARTMENT OF ELECTRICAL AND ELECTRONICS ENGINEERING, \\ SRM - UNIVERSITY RAMAPURAM CAMPUS, CHENNAI -600089
}

\begin{abstract}
This paper describes charging of mobile phones by making use of sound. Basically here the sound energy is converted into electrical energy; the main principle involved in this project is piezoelectric effect which is the conversion of mechanical force or stress into electrical energy. The Zinc Oxide strands are interceded between two electrodes in this system. The sound absorption pad is placed upon the interceded zinc oxide electrodes. When the generated mechanical waves in the form of sound waves strike the sound absorption pad, vibration occurs. This results in the flexing of the zinc oxide wires. The compressions and rare fractions are due to the sensitivity of the Zno. A nano generator is placed between the sandwiched zinc oxide electrodes. The compressions and rare fractions are given to the nano generator. The nanogenerator converts the given mechanical energy into electrical energy. The generated electrical energy is used to charge the battery.
\end{abstract}

Index Terms - sound energy, electrical energy, nanogenrator, zinc oxide nanowires, zinc oxide electrodes, piezoelectric effect.

\section{INTRODUCTION}

$\mathrm{T}$ HIS This paper describes charging of mobile phones by making use of sound. Basically here the sound energy is converted into electrical energy; the main principle involved in this project is piezoelectric effect which is the conversion of mechanical force or stress into electrical energy. Mobile phones have become an integral part of our lives and are used by us to carry out various day to day activities such as banking , navigation, entertainment, booking ,education , communication etc but the mobile phones are battery constrained devices and have limited battery life and moreover making use of mobile apps and other functions leads to even higher rate of consumption of the battery. With this project now we can charge mobile phones by shouting at it or by playing music or even by making use of unwanted noises of the surroundings when the phone is discharged and we need to make an urgent call and no plug point is available nearby .

\section{EXISTING SYSTEM}

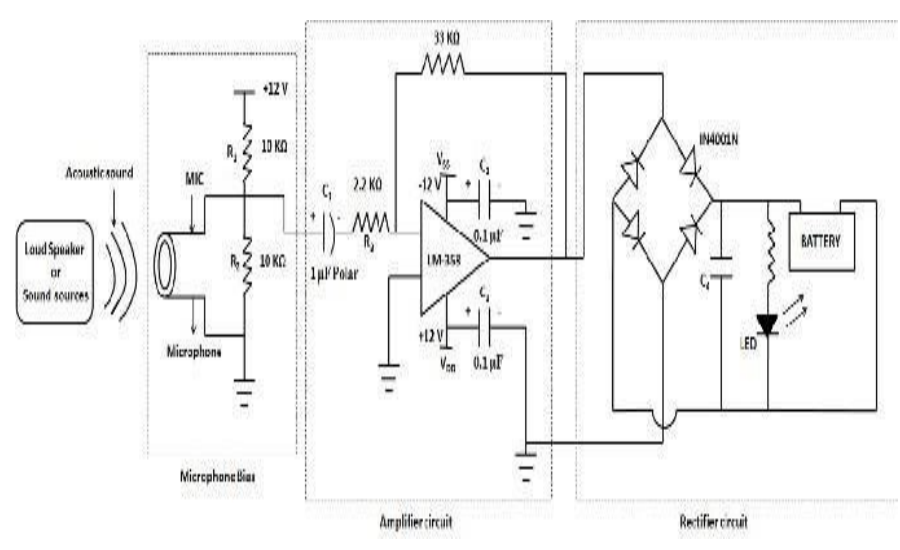

The existing system consists of a microphone to receive the sound from loud speakers and other sound sources.

A microphone is a device which converts sound energy into an electrical signal. Microphones find its applications in wide range of devices such as telecommunication devices, hearing devices, and also in many ultrasonic sensing devices or knock sensing devices. Another approach which is used currently is to make use of piezoelectric plate or a piezoelectric cell that utilizes the basic concept of piezoelectric effect for the measurement of external force, acceleration, and stress and strain by acting as a mechanic-electrical transducer. The piezoelectric technology has many advantages which has enabled its rise. Many piezoelectric materials have very high modulus of elasticity in the range of $105-115 \mathrm{~N} / \mathrm{m}^{2}$ which is even higher than that of many commonly used metals. The piezoelectric cells and sensors are extensively rugged devices 
having a very high natural frequency. They also show linear behavior for a very wide range of amplitude frequency.

\section{PROPOSED SYSTEM}

In this proposed system, the Zinc Oxide strands are interceded between two electrodes. The sound absorption pad is placed upon the interceded zinc oxide electrodes. When the generated mechanical waves in the form of sound waves strike the sound absorption pad, vibration occurs. This results in the flexing of the zinc oxide wires.. The compressions and rare fractions are due to the sensitivity of the Zno. A nano generator is placed between the sandwiched zinc oxide electrodes. The compressions and rare fractions are given to the nano generator. The nanogenerator converts the given mechanical energy into electrical energy. The generated electrical energy is used to charge the battery

Nanogenerator is a new type of device which has the ability to convert mechanical energy and also thermal energy into electrical energy. The three basic types of nano generators are :-

\section{1- Piezoelectric Nanogenerator}

\section{2- Triboelectric Nanogenerator}

3- Pyroelectric nanogenerator

The piezoelectric and triboelectric nanogenerators are the mechanical energy to electrical energy conversion devices.

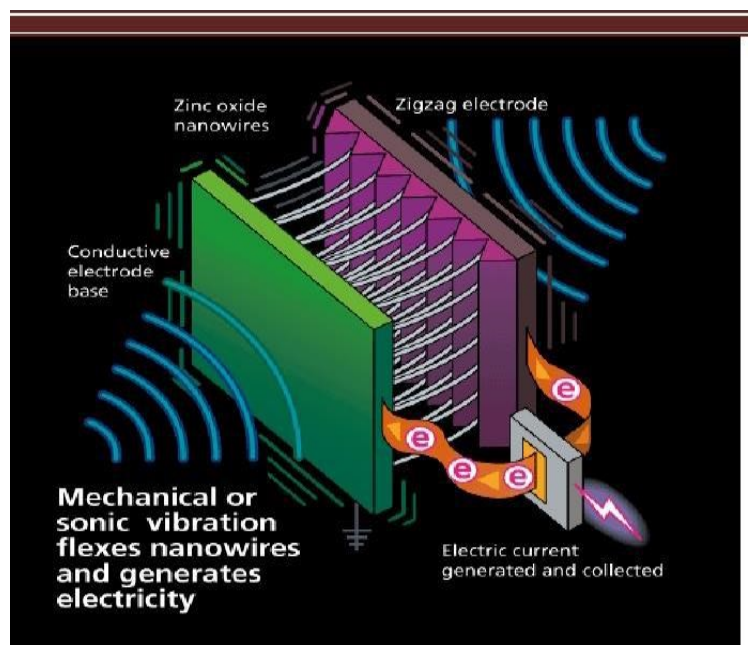

The Sound waves which are basically mechanical waves consists of compressions and rarefactions. During the compressions of the sound waves, the air molecules are compressed and hence are situated very close to each other. During the rarefactions of the sound waves, the air molecules are far apart from each other.

\section{OBJECTIVE}

To make use of sound energy which is a lesser used form of energy as compared to other forms such as solar energy, wind energy, thermal energy, and sunlight.

To make use of unwanted noises produced in traffic jams, airports, construction sites, industries and convert it to usable form of energy.

To charge the mobile phone by shouting at it or by playing music.

To be used by the user in places where no plug point is available.

\section{COMPONENTS USED}

\section{1) NANOGENERATOR}

Nano generator is a device in the form of an electronic ship that has the ability to covert mechanical energy effectively to electrical energy. The nanogenerator has also the ability of harvesting energy from human body which results from mechanical movements of the body and can also convert it to electrical power. The nanogenerator consists of $\mathrm{ZnO}$ nanowires. The $\mathrm{ZnO}$ nanowires are a type of piezoelectric ceramic material.

Whenever these interceded $\mathrm{ZnO}$ nanowires are flexed then electrical current is produced. Piezoelectric materials have the ability to generate electrical power by making use of the basic concept of piezoelectric effect. The $\mathrm{ZnO}$ nanowires have width even less than that of a human hair. The nanogenerator consists of thousands of these $\mathrm{ZnO}$ nanowires effectively interceded between two electrodes. The nanogenerator is highly flexible device and extremely compact in size and can convert even the slightest mechanical vibrations into useful electrical power. It produces $4 \mathrm{watts} / \mathrm{m} 3$ power per each nano wire it converts mechanical energy into electrical energy.

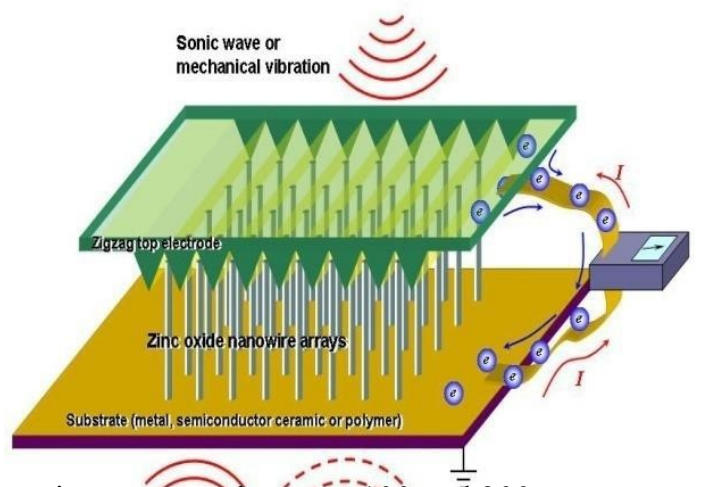

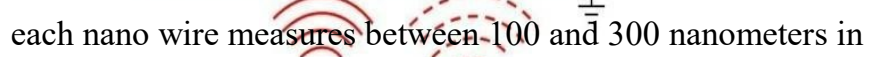
diameter(the width of the wire)! Each nano wire's length is about 100 microns; one micron $=100,000$ nanometers. To put this in perspective, note that the length of the wire (not the width) is about the same as the width of two human hairs. An array of nano wires to the substrate and places a silicone 
electrode at the other end of the wires. The electrode has a zigzag pattern on its surface.

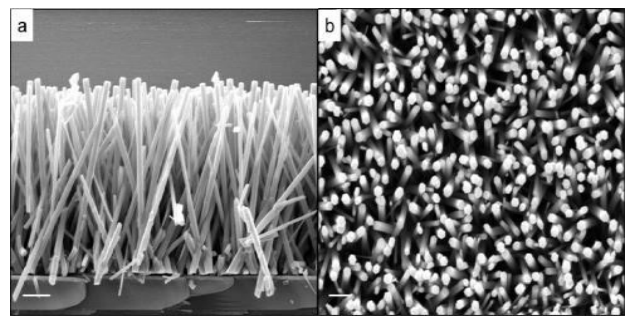

When a small physical pressure is applied to the nano generator, each nano wire flexes and generates an electrical charge. The electrode captures that charge and carries it through the rest of the nano generator circuit. The entire nano generator might have several electrodes capturing power from millions of nano wires.

\section{2) SOUND ABSORBING PADS}

The sound absorbing plates used in this technology are madeof piezoelectric materials. These are placed on top of two sandwiched $\mathrm{Zn}$ electrodes.

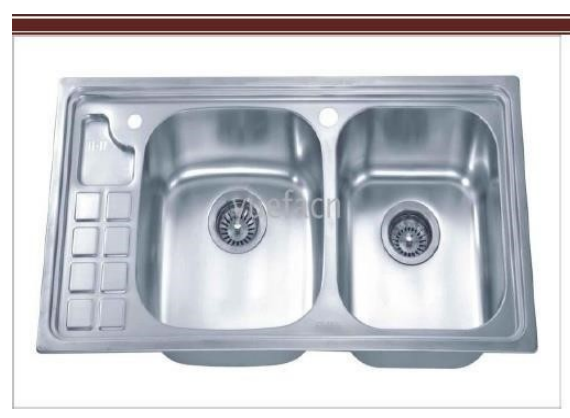

\section{3) ZNO ELECTRODES}

The Zinc Oxide strands are interceded between two electrodes in this system. The sound absorption pad is placed upon the interceded zinc oxide electrodes. When the generated mechanical waves in the form of sound waves incident on these electrodes, they are effectively transferred to the $\mathrm{ZnO}$ nanowires.

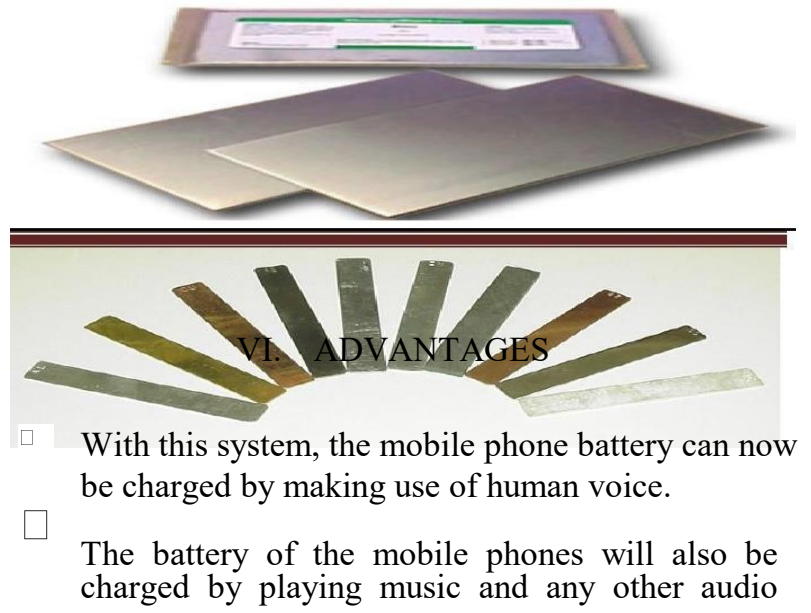

sound.

The unwanted noises of the surroundings can also be converted to useful electrical power in order to charge the mobile phone.

This device can be used in public places and also in public events to harvest energy for charging of the mobile phone battery.

The sound produced by the industries resulting from the working of different machines can also be used to charge mobile phone battery.

\section{DISADVANTAGES}

The system is on a costlier side as compared to other energy harvesting systems.

This system cannot be used in quite places and in places where the intensity of sound is very low.

The efficiency of the system is low and hence much of improvement still remains to be done in this system.

\section{EXPERIMENTS}

\section{EXPERIMENT 1:- DETERMINATION OF SOUND PRESSURE} LEVEL

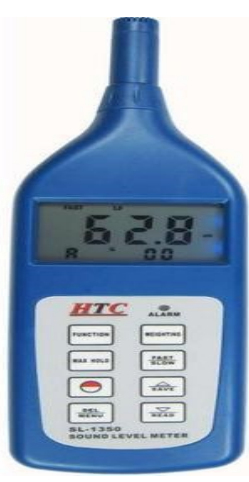

In this experiment the sound pressure level of different types of sounds found in our surroundings such as human conversation, passenger car, vacuum cleaner ,train, loud singing, buses , traffic ,noisy factory, jackhammer, construction work noises and many other sounds that are generated from different sound sources is measured by making use of HTC sound level meter SL-1350 having frequency range of $31.5 \mathrm{~Hz}$ to $8 \mathrm{KHz}$ and the corresponding values are inserted in a table. The sound pressure level is measured in terms of decibels.

\section{EXPERIMENT- 2:- DETERMINATION OF VOLTAGE GENERATED AND POWER PRODUCED}

In this experiment the voltage generated and the power produced by the system when it is exposed to different sounds generated from different sound sources and having different 
intensities and sound pressure level is found out for an increase in intensity of sound by $+20 \mathrm{~dB},+10 \mathrm{~dB},+6 \mathrm{~dB},+3 \mathrm{~dB}, 0 \mathrm{~dB},-3 \mathrm{~dB},-6 \mathrm{~dB},-10 \mathrm{~dB},-20 \mathrm{~dB}$ respectively. Also the loudness gain factor is found out and sound pressure effect and sound intensity cause is also studied.

\section{RESULTS}

\section{RESULT OF EXPERIMENT - 1}

The table is made between the different sources of sounds and the measured sound pressure level in decibels by the sound pressure level meter for each sound generated from the given sound sources of environment.

\begin{tabular}{|l|c|}
\hline SOURCES OF SOUND & $\begin{array}{l}\text { SOUND PRESSURE } \\
\text { LEVEL IN } \\
\text { DECIBELS (dB ) }\end{array}$ \\
\hline $\begin{array}{l}\text { 1.Quietest audible } \\
\text { sound for } \\
\text { persons with } \\
\text { excellent } \\
\text { hearing under } \\
\text { laboratory } \\
\text { conditions }\end{array}$ & 1.0 \\
\hline $\begin{array}{l}\text { 2. Virtual silence } \\
\text { Audiometric test } \\
\text { room }\end{array}$ & 2.20 \\
\hline $\begin{array}{l}\text { 3. Quiet whisper (1 } \\
\text { m) }\end{array}$ & 3.30 \\
\hline $\begin{array}{l}\text { 4. Quiet street } \\
\text { Whispered speech }\end{array}$ & 4.50 \\
\hline $\begin{array}{l}\text { 5. Conversation at 1 } \\
\text { m }\end{array}$ & 5.60 \\
\hline $\begin{array}{l}\text { 6. Moving car at } \\
\text { 80km/hr } \\
\text { At 30 meter } \\
\text { distance from a } \\
\text { passing train , At 3 } \\
\text { meter } \\
\text { distance from a } \\
\text { cooler }\end{array}$ & 6.70 \\
\hline $\begin{array}{l}\text { 7. Loud music in a } \\
\text { concert }\end{array}$ & 7.75 \\
\hline $\begin{array}{l}\text { 8. Traffic signal } \\
\text { vehicular noise } \\
\text { at 15 m } \\
\text { drilling machine }\end{array}$ & 8.80 \\
\hline $\begin{array}{l}\text { 9ood mixer at 1 m } \\
\text { industrial noise }\end{array}$ & \\
\hline
\end{tabular}

\begin{tabular}{|l|l|}
\hline $\begin{array}{l}\text { Newspaper printing } \\
\text { press }\end{array}$ & \\
\hline $\begin{array}{l}\text { 10. Large aircraft (150 } \\
\text { m over head) }\end{array}$ & $\mathbf{1 0 .} \mathbf{1 1 0}$ \\
\hline $\begin{array}{l}\text { 11. Chainsaw (1 } \mathrm{m}) \\
\text { Very noisy work - }\end{array}$ & 10.115 \\
\hline
\end{tabular}

\section{RESULT OF EXPERIMENT NO 2 :-}

The table is made between the change in intensity $(\mathrm{dB})$, voltage generated (volts), power produced (watts ) and also loudness gain factor and corresponding graph is plotted of change in intensity vs. voltage generated and change in intensity vs power produced

\begin{tabular}{|c|l|l|l|}
\hline $\begin{array}{l}\text { CHANGE } \\
\text { IN } \\
\text { INTENSITY } \\
(\mathrm{dB}\end{array}$ & $\begin{array}{l}\text { LOUDNESS } \\
\text { GAIN } \\
\text { FACTOR } \\
(\mathrm{L})\end{array}$ & $\begin{array}{l}\text { VOLTAGE } \\
\text { GENERATED } \\
\text { IN VOLTS }\end{array}$ & $\begin{array}{l}\text { POWER } \\
\text { PRODUCED } \\
\text { IN WATTS }\end{array}$ \\
\hline $2 .+10$ & 4.000 & 10.000 & 100.000 \\
\hline $3 .+6$ & 5.162 & 2.000 & 10.000 \\
\hline $4 .+3$ & 1.232 & 1.414 & 4.000 \\
\hline 5.0 & 1.000 & 1.000 & 1.000 \\
\hline $6 .-3$ & 0.812 & 0.707 & 0.500 \\
\hline $7 . \quad-6$ & 0.660 & 0.500 & 0.250 \\
\hline $8 .-10$ & 0.500 & 0.312 & 0.100 \\
\hline $9 . \quad-20$ & 0.250 & 0.100 & 0.010 \\
\hline
\end{tabular}



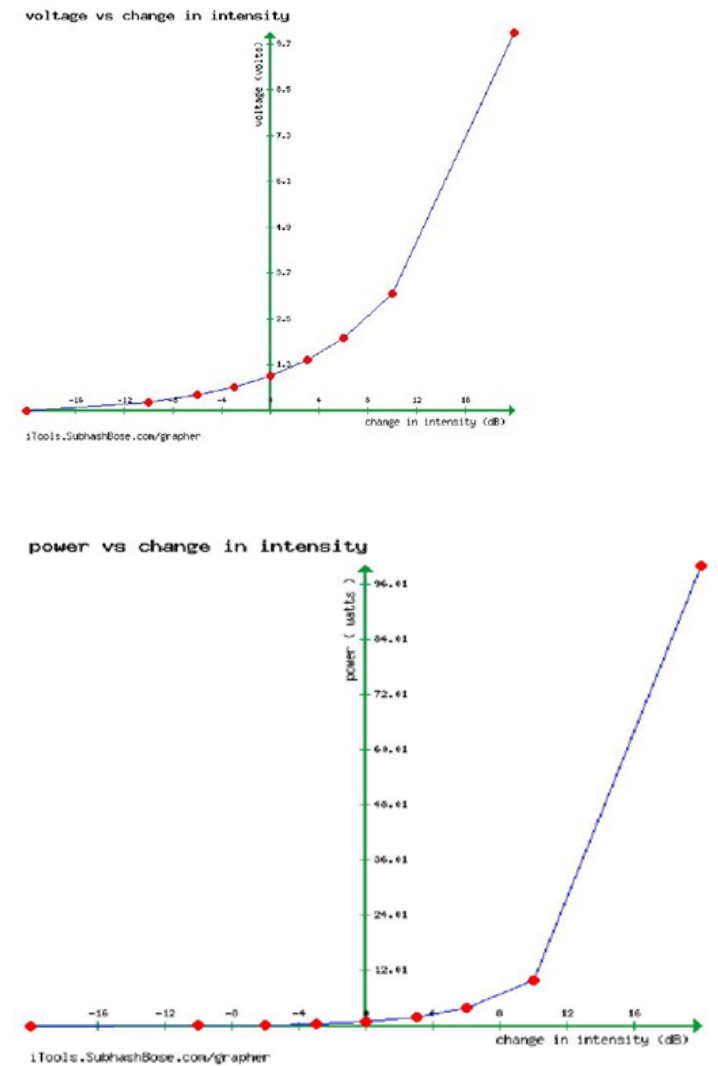

\section{FUTURE SCOPE}

$*$

This system in future will enable us to harvest Sound energy even more efficiently. It will help us to use sound energy which is a lesser known form of energy as compared to other widely used form of energies.

This system utilizes the sound energy which is also a type of green energy and no harmful chemicals and gases are released during the working of this system so it is a pollution free Energy harvesting system.

The noise pollution produced in the traffic signals by various vehicles will be harvested and then he conserved electrical power will be used to light the street lamps, traffic signals and power Various electrical appliances.

The noise generated by the flights that are present in the airport can be converted to useful electrical power and thus can be used as a source Of power for the entire airport.

The sound emerging from the nuclear fission reactions of the nuclear power plant can be converted to electrical energy and hence the total output power of nuclear reactors and its Efficiency can be increased.

The noises that are produces in industries Resulting from the working of the machines can be harvested and can further be used for powering of other machines present In the factory.

\section{CONCLUSION}

This system is highly efficient as well as pollution free and utilizes the sound energy for its working which is a green energy and also a lesser used form of energy as compared other renewable sources of energy. The sound energy is non exhaustible and easily available form of energy and it has the ability to meet the energy requirements of this entire world.

The working principal of this system is the piezoelectric effect by which the mechanical vibrations, forces, stress and strain can be converted into usable form of electrical energy.

The sound waves that are a type of mechanical wave are incident on the nanogenerator used in this system and this nanogenerator converts in into electric current.

Plenty of research and improvement still remains to be done in this system but on a positive note this system has very wide range of potential applications in various other fields such medical field, military and aerodynamics.

\section{REFERENCES}

[1] Piezo-electric terminology by Walter g. cady, Proceedings

of the Institute of Radio Engineers, Volume 18, Number 12 December, 2006.

[2] https://en.wikipedia.org/wiki/Piezoelectricity

[3] http://www.engineersgarage.com/electronic-circuits/usbmobile-charger.

[4] https://en.wikipedia.org/wiki/Sound_energy.

[5] https://en.wikipedia.org/wiki/Sound_pressure

[6]Paper-Based $\mathrm{ZnO}$ Nanogenerator Using Contact

Electrification and Piezoelectric Effects Quang Nguyen ; Baek

Hyun Kim ; Kwon,J.W.

MicroelectromechanicalSystems,Journal (Volume:24Issue3]

[7] electronics.howstuffworks.com/nanogenerator.htm 